\title{
A virada pós-colonial: experiências, trauma e sensibilidades transfronteiriças
}

The Post-Colonial Turn: Experiences, Trauma and Cross-Border Sensitivities

Le tournant postcolonial : expériences, traumatismes et sensibilités

transfrontalières

Adelia Miglievich-Ribeiro

\section{OpenEdition}

\section{Journals}

Edição electrónica

URL: http://journals.openedition.org/rccs/11077

ISSN: 2182-7435

Editora

Centro de Estudos Sociais da Universidade de Coimbra

Edição impressa

Data de publição: 1 dezembro 2020

Paginação: 77-96

ISSN: 0254-1106

Refêrencia eletrónica

Adelia Miglievich-Ribeiro, «A virada pós-colonial: experiências, trauma e sensibilidades

transfronteiriças », Revista Crítica de Ciências Sociais [Online], 123 | 2020, posto online no dia 15

dezembro 2020, consultado o 17 dezembro 2020. URL : http://journals.openedition.org/rccs/11077 


\title{
ADELIA MIGLIEVICH-RIBEIRO
}

\section{A virada pós-colonial: experiências, trauma e sensibilidades transfronteiriças*}

\begin{abstract}
Neste artigo postulo a "virada pós-colonial" como um movimento que não se limita ao debate epistemológico nem à construção estética do texto. Argumento que seu diferencial está na centralidade que dá ao que chamo "conhecimento-testemunho" a partir da experiência de um trauma coletivo: o colonialismo-racismo. Assim, suas categorias são formuladas a partir de outros lugares de fala, que são, sobretudo, "lugares de afetos". No diálogo com a "virada afetiva", explano acerca das trajetórias icônicas de Frantz Fanon e Edward Said, evidenciando as experiências do exílio, da diáspora e da hibridez que configuram, nos termos de Raymond Williams, a especial estrutura de sentimentos a impregnar tais produções intelectuais. O retorno aos autores fundantes do pós-colonial permite, portanto, extrair provocações que promovem a vitalidade da virada pós-colonial, corroborando a sua atualidade.
\end{abstract}

Palavras-chave: biografias; Edward Said; Frantz Fanon; lugar de fala; pós-colonialismo; visão de mundo.

\section{Apresentação}

Os estudos sob a rubrica pós-colonial ganharam destaque na academia ocidental a partir dos anos 1970. Emblemático neste movimento insurgente foi o livro Orientalismo. O Oriente como invenção do Ocidente (1990), do bíbrido - palestino e cidadão estadunidense - Edward Said, cuja primeira edição data de 1978. Havia, porém, um acúmulo anterior vindo das guerras de libertação das colônias africanas ao mesmo tempo que da diáspora negra, gerando uma literatura inédita. Exemplares dessa irrupção são Retrato do colonizado, precedido de Retrato do colonizador (2007 [1957]), do tunisino

\footnotetext{
Agradeço ao Laboratório de Sociologia Não Exemplar (Diretório de Grupos de Pesquisa Conselho Nacional de Desenvolvimento Científico e Tecnológico/DGP-CNPq), na pessoa de seu líder, Professor Marcelo Rosa, pela acolhida em meu pós-doutorado no Programa de Pós-graduação em Sociologia da Universidade de Brasília (PPGSol-UnB), ao longo de 2019 e início de 2020, e pelas criativas discussões que ainda nos unem em torno das teorias ontoformativas nas ciências sociais e suas afetações na produção de (in)existências.
} 
Albert Memmi, bem como as obras dos martinicanos Aimé Césaire, Discurso sobre o Colonialismo (2010 [1950]), e Frantz Fanon, Pele negra, máscaras brancas (2008 [1952]) e Os condenados da terra (2005 [1961]).

Não tenciono, nesse artigo, mapear a "virada pós-colonial" em seus distintos vieses, tendências, linhagens ou momentos, ${ }^{1}$ mas opto por eleger dois autores emblemáticos da crítica pós-colonial: Frantz Fanon (1921-1965) e Edward Said (1935-2003). Pretendo demonstrar que suas produções intelectuais são indissociáveis de suas biografias nômades e que se construíram a partir de um real e incômodo sentimento: o deslocamento - que lhes impôs uma "perspectiva alternada" (Adorno, 2008) e, consequentemente, uma intransigente busca da autonomia intelectual.

Postulo, nesse sentido, a dimensão afetiva como recurso teórico e metodológico caro às ciências sociais, tomando a experiência corpórea viva de ambos os autores pós-coloniais como especialmente férteis em uma chave fenomenológica:

Tudo aquilo que sei do mundo, mesmo por ciência, eu o sei a partir de uma visão minha ou de uma experiência do mundo sem a qual os símbolos da ciência não poderiam dizer nada. Todo o universo da ciência é construído sobre o mundo vivido, e se queremos pensar a própria ciência com rigor, apreciar exatamente seu sentido e seu alcance, precisamos primeiramente despertar essa experiência do mundo da qual ela é a expressão segunda. (Merleau-Ponty, 2006: 3)

A virada pós-colonial protagonizada por Fanon e Said subverte as teorias consagradas de uma modernidade pseudo-monolítica, colocando em primeiro plano da análise o colonialismo que entrelaçou mundos diversos, tendo a partir do século XVI redefinido as fronteiras no planeta, drástica e irreversivelmente, ao imiscuir povos, histórias e culturas, redefinindo centros e periferias. Sobretudo, a virada pós-colonial concentra-se em explicitar a "missão civilizatória" como a pior das barbáries, que desumanizou dois terços da população mundial, moldando a desigual divisão internacional do trabalho e das riquezas.

$\mathrm{Na}$ releitura das narrativas canônicas, quer liberal quer marxista, a partir das margens do sistema global (Appiah, 1997), os intelectuais pós-coloniais passam a exigir a coautoria no empenho para dar inteligibilidade ao mundo moderno, que se ergueu sobre o sistema colonial e a "práxis irracional da violência" (Dussel, 2000), ao lado da experiência transnacional dos sem-lar [unhomely em inglês]. Reivindica-se, como o nome indica, o "lugar

\footnotetext{
${ }^{1}$ A este exercício de sistematização, já me dediquei anteriormente (ver Miglievich-Ribeiro, 2017).
} 
pós-colonial" de enunciação, para vocalizar sentimentos de desenraizamento bem como o "trauma coletivo" que corroeu vítimas e algozes. Dizer o indizível é a tarefa dos/das intelectuais pós-coloniais que, para tal, redefinem categorias e conceitos que desenham outros espaços, tempos, sentimentos, vivências e, assim, reescrevem as histórias, necessariamente, no plural.

A crítica pós-colonial vem desnudar, pois, os discursos pretensa e fracassadamente assépticos da ciência dita moderna, propugnando o "conhecimento-testemunho" como legítimo. Sob esse ângulo, a virada pós-colonial oferece um plus ao acervo das ciências humanas e sociais uma vez que, ao iluminar diferentes lugares de fala, ${ }^{2}$ inserem nesse compêndio as existências, experiências e sensibilidades de corpos outros e suas relações. Os/as pós-coloniais são, aliás, também corpos que vivenciam o "entrelugar”, sendo que a partir dele interagem com/no mundo e formulam novos entendimentos.

A centralidade da raça e do racismo em suas análises intensifica a percepção da experiência corporal como condição humana, o que possibilita aliar o "desaparecimento social" aos "invariantes biológico-existenciais" (Ortega, 2005: 1879). Proponho, assim, a leitura da crítica pós-colonial como sendo capaz de emprestar singular vitalidade à "virada afetiva" nas ciências sociais contemporâneas, uma vez que, sob o olhar fenomenológico, há que se voltar às coisas mesmas (Merleau-Ponty, 2006), neste caso, à simultaneidade da existência e da corporeidade: "[eu sou a] experiência de meu corpo no mundo, [...] que dá um sentido motor às ordens verbais” (ibidem: 196). Reafirmando as identidades relacionais, os/as pós-coloniais puderam demonstrar a alteridade inventada como subalternidade e a luta pela emancipação daqueles que experienciaram, no colonialismo, a negação de si mesmos. Assim, em consonância com o existencialismo sartreano (Sartre, 1997), atestaram que o fenômeno humano só se dá em ato - é experiência corpórea - que impregna o mundo de sentidos.

Disso decorre o tema do "testemunho" que insiro nesse debate. Em geral, a terminologia aparece na literatura ou na história, mas não nas ciências sociais. Entretanto, o pós-colonial desafia as fronteiras disciplinares, o que me leva a pensar que a reflexão de Márcio Seligmann-Silva (2003) pode, também, nos dizer respeito. Para o autor, os testemunhos são narrativas intransferíveis da

\footnotetext{
${ }^{2}$ Vem de Michel Foucault (2010) a compreensão dos discursos como "vontades de verdade" que se traduzem em regras/práticas que moldam os distintos lugares de fala em disputa. A pesquisadora e feminista negra Djamila Ribeiro (2017) enfatiza o conhecimento situado e observa o lugar de fala como, não poucas vezes, "lugar de restrição da fala". O "lugar de fala", no presente artigo definido como experiências (corpóreas) partilhadas, é simultaneamente, também, o lugar das resistências e insurgências. Eis que, em uma infinda tensão saber-poder, emerge do "lugar de fala" o que Foucault chamou de "coragem da verdade" a colidir com os discursos hegemônicos.
} 
"travessia da morte" por aqueles/as que sobrevivem. A travessia - o "entrelugar" - é o lugar de fala dos/das intelectuais pós-coloniais que experimentaram o desenraizamento e os trânsitos como "afeto triste" que se reconverte, porém, em uma "capacitação política e epistemológica” pródiga a promover, também, deslocamentos de visão que expandem e subvertem o que a modernidade hegemônica consagrou como "verdade" (Brennan, 1989).

O poder da tradução pós-colonial da modernidade reside em sua estrutura "performática", "deformadora", que não apenas reavalia os conteúdos de uma tradição cultural ou transpõe valores "trans-culturalmente". A herança cultural da escravidão ou do colonialismo é posta "diante" da modernidade "não" para resolver suas diferenças históricas, em uma nova totalidade, nem para renunciar suas tradições. É para introduzir um outro lócus de inscrição e intervenção, um outro lugar de enunciação híbrido, "inadequado", através daquela cisão temporal - ou entre-tempo - [...] da agência pós-colonial. (Bhabha, 2007: 334)

O crítico literário brasileiro pós-colonial, Silviano Santiago (1978) destaca, similarmente a Homi Bhabha, o conceito de "entrelugar" como a uma reinterpretação da "mestiçagem" que não mais suporia a ideia de harmonia, mas seria relida como a experiência das lutas, tensões e violenta transculturação, ao mesmo tempo que traduziria as resistências e insurgências históricas havidas. A hibridez de que fala remonta aos versos de outro brasileiro, Oswald de Andrade (1990: 47-51):

Só me interessa o que não é meu. Lei do homem. Lei do antropófago. [...] Contra todos os importadores de consciência enlatada. A existência palpável da vida. E a mentalidade pré-lógica para o Sr. Lévy-Bruhl estudar. [...] Perguntei a um homem o que era o Direito. Ele me respondeu que era a garantia do exercício da possibilidade. Esse homem chamava-se Galli Mathias. Comi-o. [...] Antropofagia. Absorção do inimigo sacro. Para transformá-lo em totem. A humana aventura. A terrena finalidade. Porém, só as puras elites conseguiram realizar a antropofagia carnal, que traz em si o mais alto sentido da vida e evita todos os males identificados por Freud, males catequistas.

A capacidade de sentir-pensar o entrelugar é, também, marcante na escritora chicana, teórica e ativista feminista queer Glória Anzaldúa (2005), que se rebela contra os essencialismos identitários e os binarismos modernos que produziram a ficção da alteridade absoluta. Assim, o entrelugar que habita é, em um só tempo, desconforto e liberdade, que recusa qualquer espécie de classificação rígida. 
É de chamar atenção o quão extenso é o rol dos/das críticos/as pós-coloniais - tão largo quanto diverso, o que impossibilita chamá-lo de "escola". A exemplo, temos o sociólogo português Boaventura de Sousa Santos (2004) que batiza sua obra como "pós-colonial de oposição", uma contundente crítica ao opressor paradigma moderno que, por "indolência" e "arrogância" - em seus termos - desprezou as chances de construção de uma "vida decente" no planeta Terra. ${ }^{3}$

Tomo os/as fundadores/as do pós-colonial para análise, reiterando que Fanon e Said apontam para uma epistemologia descolonizadora que, ao invés de cegar o observador diante do real, alarga o escopo de visão. Tal desafio, na análise desenvolvida, quer "interrogar”, em uma alusão a Bhabha (2007), o "lugar pós-colonial" de Fanon e Said, que lhes dá a prerrogativa de uma visão mais ampliada sobre o "pluriversal" (Mignolo, 2003), em substituição ao universal.

\section{Frantz Fanon}

O intelectual camaronês Achille Mbembe recorda que Fanon (2011: 1) "pertence a uma geração que passou, por duas ou três vezes, pela provação do desastre e, através da experiência de fim do mundo que toda a catástrofe consigo acarreta indivisamente, pela provação do mundo", o que faz de sua experiência, o desastre e a catástrofe, e dos sentimentos dela emanados, os elementos constitutivos de seu Pele negra, máscaras brancas (Fanon, 2008 [1952]) e também de Os condenados da terra (Fanon, 2005 [1961]).

Se o racismo (antinegritude) afeta profundamente a relação corpo-linguagem-lei, anulando subjetividades, não é de se estranhar os termos recorrentes em sua obra: "saída da grande noite", "desordem absoluta", "argamassa do sangue e da cólera", "emergência", "libertação", "renascimento", "restituição", "surgimento do homem novo" (Mbembe, 2011).

O trauma experimentado, não como indivíduo isolado, mas como uma "estrutura de sentimentos" (Williams, 2011), ${ }^{4}$ faz com que se conceba o processo revolucionário como uma catarse. Fanon imprimia, assim, a marca indelével das produções pós-coloniais, a inseparabilidade entre infra e superestrutura.

\footnotetext{
${ }^{3}$ Em "Por uma razão decolonial: desafios ético-político-epistemológicos à cosmovisão moderna" (Miglievich-Ribeiro, 2014), conduzo o diálogo entre Boaventura de Sousa Santos e Walter Mignolo, na identificação da "hermenêutica diatópica" do primeiro com a "hermenêutica pluritópica" do segundo. ${ }^{4}$ Nas palavras de Raymond Williams (2011:35), “O que me parece especialmente importante nessas estruturas de sentimentos em transformação é que elas [...], embora correspondam muito de perto a uma verdadeira história social de homens vivendo em relações sociais reais e em transformação, precedem [...] as alterações mais reconhecíveis nas instituições formais e nas relações sociais que constituem a história mais acessível e, de fato, mais habitual".
} 
Nas colônias, a infraestrutura é igualmente superestrutura. A causa é a consequência: é-se rico porque branco, é-se branco porque rico. Por isso as análises marxistas devem sempre ser levemente modificadas cada vez que se aborda o problema colonial. Não são as usinas, nem as propriedades, nem as contas no banco que caracterizam a classe dirigente. A espécie dirigente é primeiramente aquela que vem de fora, aquela que não se assemelha aos autóctones, os outros. (Fanon, 2005: 9)

O sistema colonial é por ele descrito como uma modalidade de loucura. Não se trata de uma figura de linguagem. Os estudos fanonianos propugnam as teias entrelaçadas entre o plano sócio-político-econômico e a "desordem mental”, e também o "desajustamento sexual”, forjado nas práticas colonialistas e racistas.

[...] o negro vive uma ambigüidade extraordinariamente neurótica. Com vinte anos, isto é, no momento em que o inconsciente coletivo é mais ou menos perdido, ou pelo menos difícil de ser mantido no nível consciente, o antilhano percebe que vive no erro. Por quê? Apenas porque, e isso é muito importante, o antilhano se reconheceu como preto, mas, por uma derrapagem ética, percebeu (inconsciente coletivo) que era preto apenas na medida em que era ruim, indolente, malvado, instintivo. Tudo o que se opunha a esse modo de ser preto, era branco. Deve-se ver nisso a origem da negrofobia do antilhano. No inconsciente coletivo, negro = feio, pecado, trevas, imoral. Dito de outra maneira: preto é aquele que é imoral. Se, na minha vida, me comporto como um homem moral, não sou preto. Daí se origina o hábito de se dizer na Martinica, do branco que não presta, que ele tem uma alma de preto. A cor não é nada, nem mesmo a vejo, só reconheço uma coisa, a pureza da minha consciência e a brancura da minha alma. (Fanon, 2008: 162)

Leitor atento de Fanon, o pós-colonial Bhabha (2007: 35), um dos expoentes dos estudos subalternos indianos, aprofunda a percepção de Fanon de que as identidades são "zonas de luta política". Para ele, o ato de estereotipar é a atitude ambivalente, "de projeção e de introjeção, estratégias metafóricas e metonímicas, deslocamento, sobredeterminação, culpa, agressividade, o mascaramento e cisão de saberes 'oficiais' e fantasmagóricos para construir as posicionalidades e oposicionalidades do discurso racista" (ibidem: 125).

O poder da tradução pós-colonial da modernidade reside em sua estrutura "performática”, "deformadora”, que não apenas reavalia os conteúdos de uma tradição cultural ou transpõe valores "transculturalmente". A herança cultural da escravidão ou do colonialismo é posta "diante" da modernidade "não" para resolver suas diferenças 
históricas, em uma nova totalidade, nem para renunciar suas tradições. É para introduzir outro lócus de inscrição e intervenção, um outro lugar de enunciação híbrido, "inadequado", através daquela cisão temporal - ou entretempo - [...] da agência pós-colonial. (Bhabha, 2007: 3)

Como sugere Mbembe (2011), se Os condenados da terra era o livro da época da práxis revolucionária, Pele negra, máscaras brancas melhor introduz o mundo pós-colonial ou o pensamento-mundo que testemunha o processo de descentramento do conhecimento. Ainda atuais, ambas as obras são hoje trazidas para a compreensão dos novos colonialismos que reproduzem a "lógica do cerco", em que diversos processos de racialização funcionam simultaneamente como ideologia e dispositivo de segurança ao institucionalizar a violência sobre territórios e culturas.

Como é sabido, Jean-Paul Sartre prefaciou e assumiu pessoalmente a divulgação de Os condenados da terra. Como assinala Antonio Sérgio Guimarães (2019), em que pese não haver informações sobre se Sartre citou Fanon em suas conferências, o impacto da obra de Fanon sobre Sartre foi descrito não poucas vezes por Simone de Beauvoir em seus diários, o que nos permite concluir de que o existencialismo aprendeu muito com o "conhecimento-testemunho" dos/das intelectuais das margens.

Nessa perspectiva, mais do que um dos fundadores dos estudos pós-coloniais, Fanon mantém-se como inspiração para sua vitalidade, sempre que a institucionalização nos departamentos universitários - representando, em tese, o êxito da virada pós-colonial - ameaça esvaziar a potência original da crítica, que quer derrubar os muros que reificaram a alteridade.

\section{Edward Said}

Ao lado de Fanon, Said é o autor de um dos textos-fundantes da virada pós-colonial: Orientalismo. O Oriente como invenção do Ocidente (1990 [1978]). Sua análise desconstrucionista dos textos literários que compõem o cânone universal em verdade "ocidental", desvela a imensa teia de histórias entrelaçadas, reiteradamente silenciadas, que se opõe aos estereótipos (irracional, primitivo, sensual, vicioso, violento, retrógrado e outros) com os quais o Oriente é até hoje narrado, e que sustentam

[...] um estilo de pensamento baseado em uma distinção ontológica e epistemológica feita entre "o Oriente" e (a maior parte do tempo) "o Ocidente". Desse modo, uma enorme massa de escritores, entre os quais estão poetas, romancistas, filósofos, teóricos políticos, economistas e administradores imperiais, aceitou a distinção básica entre Oriente e Ocidente como ponto de partida para elaboradas teorias, épicos, romances, 
descrições sociais e relatos políticos a respeito do Oriente, dos seus povos, costumes, "mente", destino e assim por diante. (Said, 1990: 14)

Said, no diálogo com o pós-estruturalismo de Michel Foucault, explicita as relações de saber-poder que inventaram o Oriente como o Outro absoluto da Europa. O orientalismo como discurso foi, assim, construído por um vocabulário, imagens e doutrinas que se institucionalizaram. Mesmo que a expressão possa ter caído em desuso, infelizmente, não se pode dizer o mesmo da imaginação que corrobora o estigma acerca do Oriente.

A narrativa orientalista era forjada com um imenso investimento material que redundou na essencialização do oriental e, também, do ocidental, o primeiro reunindo em si a totalidade dos atributos negativos, enquanto ao segundo era reservada a condição de superioridade. Ainda mais injusto foi que, para tomar o Oriente como objeto, este foi destituído de história, logo, sequestrou-se sua agência. Nas palavras de Said (1990: 113),

[...] o tempo verbal que empregam é o eterno atemporal; transmitem uma impressão de repetição e força; são sempre simétricas e, ainda assim, diametralmente inferiores a um equivalente europeu, que ora é especificado, ora não. Para todas essas funções, basta frequentemente usar o simples elemento de ligação é.

A crítica pós-colonial é, portanto, uma "leitura em contraponto". Diaspórico e transfronteiriço, Said opera necessariamente no modo tradução. ${ }^{5}$ Em Representações do intelectual (2005), alude ao fato de que o exilado não é somente o ser forçado a viver longe de casa, mas também aquele que experimenta, o tempo todo, a sensação de que sua casa não é tão distante assim, estando permanentemente ligado a ela. Um elo que se faz físico, "embora torturante e vazio".

Há algo fundamentalmente desconcertante nos intelectuais que não têm escritórios seguros, nem território para consolidar e defender; por isso, a auto-ironia é mais frequente do que a pomposidade, a frontalidade melhor do que a hesitação

\footnotetext{
${ }_{5}^{5}$ Em Reflexões sobre o exílio e outros ensaios (2003), Said conta que nasceu palestino em Jerusalém, em 1935, durante o mandato britânico na Palestina, tendo o inglês e o árabe como seus idiomas nativos. Relata como seu pai fugiu da Palestina para os Estados Unidos da América (EUA) a fim de não servir no exército turco tendo obtido, por isso, desde o fim da Primeira Guerra Mundial, a cidadania estadunidense que transmitiu aos filhos, mas não à sua mulher - mãe de Edward Said. Por isso, a família instalou-se no Egito onde o pai se tornou um próspero comerciante. No Cairo, Said estudou nas escolas coloniais britânicas e seguiu a formação religiosa protestante anglicana, sendo um árabe entre os ingleses. Valendo-se da nacionalidade secundária do pai, migrou para os EUA onde construiu sua carreira intelectual.
} 
e o gaguejo. Mas não há como evitar a realidade inescapável de que tais representações por intelectuais não vão trazer-lhes amigos em altos cargos nem lhes conceder honras oficiais. É uma condição solitária, sim, mas é sempre melhor do que uma tolerância gregária com o estado das coisas. (Said, 2005: 17)

Said $(2005,2007 b)$ menciona a exigência de uma "erudição implacável" que, combinada a um "sentido do dramático e do insurgente", faz o intelectual "deslocado" entregar-se obsessivamente ao rastreio de fontes alternativas e à "exumação" de documentos enterrados, aproveitando todas as oportunidades para falar e cativar o público, saindo-se melhor nos embates e deixando pelo caminho os desafetos e os admiradores.

Devemos, pois, ler os grandes textos canônicos, e talvez também todo arquivo da cultura européia e americana pré-moderna, esforçando-nos por extrair, entender, enfatizar e dar voz ao que está calado, ou marginalmente presente ou ideologicamente representado em tais obras. (Said, 1995: 104)

Said - humanista crítico em nome do humanismo, como se autoproclamava (cf. Said, 2007a) - questionou o humanismo como patrimônio de uma elite, um enciclopedismo a manter intocável a todo custo (Said, 2007b). No sentido oposto, articulou-o a um incansável ativismo anticolonialista. Seu "lugar de afetos" é o da resistência teórica e política contra a força homogeneizadora e mutiladora de uma história linear. Reforça-se aqui a experiência do deslocamento como uma "estrutura de sentimentos", nos termos de Raymond Williams (2011).

A luta de Said pela causa palestina é um fator notável de sua biografia. Sobretudo, após o 11 de Setembro de 2001, viu-se interpelado a reagir à onda de estereótipos dirigidos à cultura árabe nos Estados Unidos, tais como os que associam brutalidade e violência aos muçulmanos em geral, e que reduzem o islamismo a uma religião fanática e cruel (inclusivamente contra as mulheres). Said constitui-se, assim, como um crítico contumaz da produção midiática ocidental sobre o Islã:

Ao invés dos estudiosos, nós, frequentemente, encontramos somente jornalistas fazendo declarações extravagantes, que são instantaneamente captadas e dramatizadas pela mídia. Paira sobre seu trabalho um conceito escorregadio ao qual eles [jornalistas] constantemente chamam de "fundamentalismo", uma palavra que passou a ser associada quase automaticamente ao Islã [...]. As associações criadas deliberadamente entre o Islã e o fundamentalismo garantem que o leitor comum passe a ver ambos como sendo essencialmente a mesma coisa [...], daí, o reforço a cada fato negativo 
associado ao Islã - sua violência, primitivismo e atavismo, qualidades ameaçadoras é perpetuado. E tudo isso sem nenhum esforço sério de definir o termo "fundamentalismo", ou dar um significado preciso ao "radicalismo", ao "extremismo", sequer contextualizando esses fenômenos (por exemplo, dizer que $5 \%$, ou $10 \%$, ou $50 \%$, de todos os muçulmanos são fundamentalistas). (Said, 2007a: xvi-xvii; tradução minha)

Seu lugar de fala expressava os sentimentos cosmopolitas e anti-segregacionistas que balizam a crítica pós-colonial. Cabe provocar a indagação se a adesão ao pós-estruturalismo é o bastante para se definir virada pós-colonial. A resposta é não. O filósofo ganês Kwane Anthony Appiah, em $\mathrm{Na}$ casa de meu pai. A África na filosofia da cultura, ajuda-nos a justificar a resposta:

O pós-colonialismo é posterior a isso tudo [literatura pós-realista, política pós-nativista, solidariedade transnacional, pessimismo]: e seu pós, como o do pós-modernismo, é também um pós que contesta as narrativas legitimadoras anteriores. E as contesta em nome das vítimas sofredoras de "mais de trinta repúblicas". Mas contesta-as em nome de um universal ético, em nome do humanismo [...]. E baseado nisso, ele não é um aliado do pós-modernismo ocidental, mas um adversário: com o que acredito o pós-modernismo possa ter algo a aprender. (Appiah, 1997: 216)

Em suma, mais do que um estilo estético ou mesmo um gesto epistemológico, o pós-colonial é um ato ético e político diante da interdição à fala da alteridade em seus desdobramentos os mais nefastos. Nesse movimento, o bíbrido Said é paradigmático.

\section{Lócus de enunciação como lugar de afetos}

A hipótese da "estrutura de sentimentos" de Williams (2011) como lócus de emergência de ideias-força leva-nos à ênfase nas experiências, práticas, vivências, afetos que cotidianamente nos constituem como sujeitos, também, de nossas falas. Chama-se de "contextualização radical" o intento de Williams em procurar as experiências nascentes que se expressam como "consciência prática". As "estruturas de sentimentos" são um sentido peculiar de vida: uma comunhão de sentidos, firme como uma estrutura, mas que se realiza nos mais sutis movimentos de nossa vida cotidiana (ibidem).

Assim, uma sociologia dos/das intelectuais profícua parece advir da percepção precisa destes homens e mulheres como partícipes de uma "comunidade de sentido" que se ergue nas dinâmicas sociais, nas lutas políticas e tende a abranger um certo quadro geracional - não exclusivamente em termos de datação histórica, mas como um fluxo de consciência 
vivenciado por algumas pessoas em suas histórias de vida, afetadas estas por uma atmosfera comum.

Lawrence Grossberg (1997) observa que os "aparatos afetivos" ultrapassam a produção discursiva e a noção de representação para materializar existências e coexistências. Afetar-se é, pois, coexistir, compartilhar, com outros, uma realidade comum. O afeto é energia, humores, emoções, inflexões, desejos, paixões, sensações que produzem as experiências tais como são vivenciadas. O afeto produz "presença", reunindo movimentos vários, de tempos múltiplos, em lugares físicos e corpos diferentes de maneira a se dar o "encontro concreto" no mundo.

Para fins de minha reflexão, proponho o lugar pós-colonial como este encontro que reuniu distintos corpos e mentes em uma consciência intersubjetiva inédita, mediante um dado "estoque de conhecimento" (Schütz, 1979: 172), dotado de uma potência desestabilizadora. Bebendo da fonte do filósofo dos afetos, Michael Hardt explica:

Spinoza propõe uma correspondência entre o poder de agir e o poder de ser afetado. Isto se aplica igualmente à mente e ao corpo: o poder da mente para pensar corresponde a sua receptividade às ideias externas; e o poder do corpo para agir corresponde à sua sensibilidade aos outros corpos. Quanto maior o nosso poder de ser afetado, maior o nosso poder de agir. [...] Para o autor, os afetos podem ser ações - determinadas por causas internas; ou paixões - determinadas por causas externas. Existem as razões, ou ações da mente, que juntamente com as ações do corpo, poderiam levar, provocativamente, a uma razão corpórea; e existem as paixões, tanto da mente quanto do corpo. A perspectiva dos afetos não supõe que razão e paixão sejam a mesma coisa, mas, em vez disso, focalizam a ambas num continuum. (2015: $\mathrm{x}$ )

Defendo, por isso, a plausibilidade de se reconhecer na virada pós-colonial - em sua imensa gama de autores/as, cada qual em sua singularidade -, uma comunhão entre experiência e consciência a partir de situações e sensações que, sobre eles e elas, exerceram real impacto num espaço e época determinados, produzindo em algum momento uma identidade para os/as participantes desse movimento epistemológico e ontológico. Postulo, nessa perspectiva, que o exílio ou a diáspora, a subalternidade e o racismo constituem-se como afetos comuns, em uma intrincada rede de relações complexas que se traduzem nas dinâmicas reais da vida que também marcam um tipo de consciência.

Afeto comum é uma onda, um atrito, uma conexão de algum tipo que tem um impacto. É transpessoal ou pré-pessoal - não é sobre os sentimentos de uma pessoa 
se tornarem os de outra, mas sobre corpos literalmente afetando uns aos outros e gerando intensidades: corpos humanos, corpos discursivos, corpos de pensamento, corpos de água. (Stewart, 2007: 128; tradução minha)

Podemos ler Fanon e Said como tendo ambos emergido de uma situação de trauma. Ambos narram a dor em função de um mesmo fenômeno que designamos colonialismo. Said conta em Fora do lugar (2004) que, em adulto, sempre que voltou para visitar seus parentes em Jerusalém negava-se, nos aeroportos, a dizer que seguia para Israel, optando por chamar seu destino de Palestina. A Palestina vivia nele. Fanon, por sua vez, estudante em Paris, experimentava em sua pele negra a inconcebível violência do racismo. Reduzido a um estereótipo, a dor era seu "lugar de fala" e seu pensamento autônomo o antídoto:

Mamãe, olhe o preto, estou com medo! Medo! Medo! [...] Lancei sobre mim um olhar objetivo, descobri minha negridão, minhas características étnicas - e então detonaram meu tímpano com a antropofagia, com o atraso mental, o fetichismo, as taras raciais, os negreiros, e sobretudo com 'y'a bon banania. (Fanon, 2008: 105-106)

Não é gratuito que Fanon tenha intitulado o capítulo que contém o excerto acima como "A experiência vivida do negro" (itálico meu), o que para Joaze Bernardino (2016: 506) implica uma remissão à fenomenologia, no caso, à percepção "do corpo negro pelo outro imperial e racista". Concomitantemente, o afeto que o atingiu origina o novo, a afetar o mundo. Como analisou Bernardino, "este mesmo corpo, objetificado e visto, é o corpo que vê, age e reflete conscientemente sobre o mundo" (ibidem). Não há, para os pós-coloniais, a cisão entre corpo e psiquê ou corpo e espírito: o corpo, visto pelo outro, ganha a consciência de como é percebido, ao mesmo tempo, também percebe aquele que o vê.

Os corpos tocam-se em uma atmosfera na qual as sensações, atividades e consciências se constituem, podendo se expressar pelo tédio, medo, indignação, ira, alegria, entusiasmo, ânimo, esperança ou outras formas. A ambiência é uma realidade externa ao ser, porém, sentida no ser, podendo ainda, sofrer outras interferências que aumentam, diminuem ou mudam as sensações.

Como o que Rolland Barthes chama de "terceiro significado", são imanentes, obtusos e erráticos, em contraste com o "significado óbvio" da mensagem semântica e da significação simbólica. Eles não funcionam como "significados" per se, mas sim na medida em que ganham densidade e textura enquanto se movem através de corpos, 
sonhos, dramas e mundos sociais de todos os tipos. O seu significado reside nas intensidades que eles promovem e nos pensamentos e sentimentos que tornam possíveis. A questão que levantam não é o que eles podem significar em uma ordem de representações, ou se eles são bons ou ruins em um esquema abrangente de coisas, mas aonde eles poderiam ir e que modos potenciais de conhecer, se relacionar e perceber as coisas já estão de alguma forma presentes neles em um estado de potencialidade e ressonância. (Stewart, 2007: 3; tradução minha)

Os afetos conformando o lócus pós-colonial de onde falam os/as intelectuais parece-me ser uma promissora chave de interpretação deste giro epistemológico e ontológico. O texto pós-colonial é um "lugar de fala", profundamente afetado por uma situação de sofrimento intersubjetivo gerado por deslocamentos, que se deixa marcar pelo paradoxo da necessidade do grito e da impossibilidade de romper o silêncio. Como analisou Sergio Rouanet relativamente a todas as formas de opressão, "as regras de sujeição são também as regras de subjetivação” (apud Herculano, 2012: 17). Aquilo que subordina a pessoa também produz sua agência.

\section{Considerações finais}

Bhabha escreve que as abordagens pós-coloniais "emergem do testemunho colonial dos países do Terceiro Mundo e dos discursos das 'minorias' dentro das divisões geopolíticas de Leste e Oeste, Norte e Sul” (2007: 275; itálico meu). Assumindo a condição de narradores/as, aqueles/as que experenciaram o "sentenciamento da história": a exploração, o preconceito, a desumanização, os/as intelectuais pós-coloniais são mestres/as em expor as antinomias e as ambivalências subjacentes ao paradigma da modernidade. Mais que proponentes de uma uma pós-modernidade, como já assinalado, eles e elas são arautos de uma contramodernidade a combater os mitos do telos, da evolução linear e do progresso, típicos do vernáculo da modernidade eurocêntrica.

Aliás, Sandra Goulart Almeida (2013: 695) recorda que a expoente feminista dos estudos subalternos indianos, Gayatri Spivak, afirma que o pós-colonial é, ele próprio, o atestado do fracasso da descolonização, lamentando que sua crítica, como intelectual privilegiada e cosmopolita, ainda se faça necessária no longo e áspero processo até que as vozes subalternas se tornem audíveis.

Os estudos pós-coloniais retomam as experiências africanas, ameríndias e asiáticas e as inserem na produção de teorias sociais sobre o mundo. Isto significa que não se constituem simplificadamente em uma teoria social das periferias. Ora, a virada pós-colonial desconstrói todos os binômios modernos, revelando, assim, o caráter espúrio da dicotomia centro-periferia. Os estudos pós-colonais valem-se, para isso, de inéditas correntes intelectuais, 
desde a crítica literária e artística à psicanálise e à crítica psiquiátrica, dos estudos da raça e das diásporas (critical race studies), da diferença sexuada (feminismo, queer) aos estudos subalternos (subaltern studies), valorizando os inúmeros tipos de intercâmbios (public culture), que expandem e/ou refutam os métodos e os resultados a que as ciências humanas então consagradas teriam chegado (Mbembe, 2011: 6-7), uma vez que a virada pós-colonial explicita sobretudo a hibridez/transculturação/trânsitos das produções intelectuais.

A virada pós-colonial emerge em tempos de catástrofe como testemunho, para poder comunicar o incomunicável: a tragédia. O "afeto triste", em um primeiro momento, é, enfim, traduzido como experiência libertadora, que enche de oxigênio os pulmões, literalmente. Assim, distintamente de Arif Dirlik (1994), sugiro que os estudos pós-coloniais são muito mais do que "aplicações" dos métodos originários no Primeiro Mundo, apenas modificados por "sensibilidades do Terceiro Mundo" (ibidem). O que defendo é a inseparabilidade da sensibilidade e do pensamento em suas melhores elaborações. Em outras palavras, as sensibilidades produzem teorias, não como algo a se censurar na prática da ciência, mas a potencializá-la, o que implica uma ressignificação epistemológica, sem dúvidas, que desafie as ciências sociais produzidas hegemonicamente.

Fala-se aqui de "conhecimento-testemunho". Para Carlos Ginzburg (2011: 20), "a escrita é vista como enunciação posicionada em um campo social marcado por conflitos, em que a imagem da alteridade pode ser constantemente colocada em questão". Os estudos pós-coloniais produzem, pois, o redimensionamento e a expansão da inteligibilidade do mundo.

Os fundadores do pós-colonial, aqui em tela, não são relativistas culturais, uma tendenciosa redução da virada pós-colonial nem se aliam por uma adesão unívoca ao pós-estruturalismo. Sabem que o corpo torturado e assassinado é um dado acessível em si mesmo, mais palpável é impossível. Levam a sério a linguagem também, sabendo do saber-poder nela contido que legitima que alguns corpos - e não outros - sejam violentados. Mais fundamental do que o debate estritamente epistemológico, como explanado neste artigo, o gesto pós-colonial se define pelo reconhecimento das "ontologias outras", ${ }^{6}$ que nunca couberam no paradigma moderno euro-americano.

Marcelo Rosa (2019) traz a noção de "desconcerto" - disconcertment em inglês - para compreender os dilemas da produção e recepção do trabalho

\footnotetext{
${ }^{6}$ Cabe a referência ao movimento geral da "virada ontológica" na antropologia cujos autores emblemáticos são, entre outros, Bruno Latour (1994), Eduardo Viveiros de Castro (2007) e Philippe Descola (2015). O movimento é uma resposta à "virada linguística", ao evocar o primado da existência sobre o conhecimento.
} 
do sociólogo nigeriano Akinsola Akiwowo que, por meio de seu conceito de asuwada, insere na explicação sociológica crenças, sensibilidades e sociabilidades rotuladas como "pré-modernas", a exemplo da indistinção entre indivíduo e coletivo ou entre natural e sobrenatural. Assim, o designado "pré-moderno" é, de fato, uma "ontologia desconcertante" aos olhos da matriz ocidental do conhecimento, uma vez que "uma boa parte da teoria que lemos e produzimos não se submete ao desconcerto ontológico, porque não encontra, teórica e empiricamente, outros mundos vividos que não sejam 'modernos'” (Rosa, 2019: 404). Entretanto, uma sociologia aberta aos "desconcertos" parece se tornar uma inegável possibilidade epistemológica e metodológica a potencializar a teoria social/sociológica. Não precisa ser pós-colonial para inferir isso. Mas, não chega a esta conclusão o/a intelectual que não experimente o "desassossego" como uma condição existencial.

A virada pós-colonial, exemplar nas obras de Fanon e Said, é também luta por reconhecimento (Honneth, 2003), ${ }^{7}$ a esbarrar com os neocolonialismos na arena científica. Deslocando dispositivos coloniais de poder nas direções Sul-Norte e Sul-Sul, as teorias sociais são convulsionadas.

Por outro lado, como observa Paulo Henrique Martins (2019), a produção de inteligibilidade acerca do real não é uma prerrogativa dos/das acadêmicos/as. Há importantes movimentos intelectuais que transpassam tal espaço e produzem conhecimentos valiosos nas mais diversas instituições sociais, igrejas, sindicados, organizações não-governamentais, movimentos sociais, coletivos e ativismos. Os estudos pós-coloniais são pioneiros no empenho em articular linguagens e saberes cotidianos e populares para somar à produção de sentidos no mundo.

Haverá, entretanto, sempre o risco de se trair os propósitos fundantes, quando os/as novos/as autoproclamados/as pós-coloniais se afastam dos afetos nos quais este conhecimento emergiu, reproduzindo hieraquias e se estabelecendo, ao seu modo, como cânones. Podem ainda ser eclipsados na academia ou mantidos na categoria dos saberes periféricos e exóticos, o que também é um "desperdício" (Santos, 2004). Em suma, os desdobramentos da virada pós-colonial estão em aberto. Sua vitalidade dependerá da criatividade e da densidade das análises que se colocam sob esta rubrica.

Revisto por Ana Sofia Veloso

\footnotetext{
7 Não é um acaso que Axel Honneth, teórico crítico e representante da terceira geração de Frankfurt, em seu livro Luta por reconbecimento. A gramática dos conflitos sociais (2003) tenha Fanon como fonte. Um traço do pós-colonial é a constante tensão entre centro e margem, que cria fronteiras marcadas pela indecidibilidade, como propôs Bhabha (2017).
} 


\section{Referências bibliográficas}

Adorno, Theodor (2008), Mínima Moralia. Reflexões a partir da vida lesada. São Paulo: Azougue. Tradução de Gabriel Cohn.

Almeida, Sandra Regina Goulart (2013), "Intervenções feministas: pós-colonialismo, poder e subalternidade", Estudos Feministas, 21(2), 689-700. Consultado a 28.04.2020, em https://www.scielo.br/scielo.php?pid=S0104-026X2013000200019 \&script=sci_abstract\&tlng=pt.

Andrade, Oswald de (1990), A utopia antropofágica. A antropofagia ao alcance de todos. São Paulo: Globo.

Anzaldúa, Gloria (2005), "La conciencia de la mestiza/rumo a uma nova consciencia”, Revista Estudos Feministas, 13(3), 704-719. Tradução de Ana Cecilia Acioli Lima. Consultado a 28.04.2020, em https://www.scielo.br/scielo. php?script=sci_arttext\&pid=S0104-026X2005000300015.

Appiah, Anthony (1997), Na casa de meu pai. A África na filosofia da cultura. Rio de Janeiro: Contraponto. Tradução de Vera Ribeiro.

Bernardino, Joaze (2016), "A prece de Frantz Fanon: oh, meu corpo, faça sempre de mim um homem que questiona!”, Civitas - Revista de Ciências Sociais, 16(3), 504-521.

Bhabha, Homi (2007), O local da cultura. Belo Horizonte: Editora da UFMG. Tradução de Myriam Ávila.

Brennan, Timothy (1989), Salman Rushdie and the Third World. Myths of the Nation. London: Macmillan.

Césaire, Aimé (2010), Discurso sobre o colonialismo. Florianópolis: Letras Contemporâneas. Tradução de Noémia de Sousa.

Descola, Philippe (2015), "Além de natureza e cultura", Tessituras - Revista de Antropologia e Arqueologia, 3(1), 7-33. Tradução de Bruno Ribeiro. Consultado a 28.04.2020, em https://periodicos.ufpel.edu.br/ojs2/index.php/tessituras/article/view/5620.

Dirlik, Arif (1994), "The Postcolonial Aura: Third World Criticism in the Age of Global Capitalism", Critical Inquiry, 20(2), 328-356.

Dussel, Enrique (2000), "Europa, modernidad y eurocentrismo", in Edgardo Lander (org.), La colonialidad del saber: eurocentrismo y ciencias sociales. Buenos Aires: CLACSO, 246-255.

Fanon, Frantz (2005), Os condenados da terra. Juiz de Fora: UFJF. Tradução de José Laurênio de Melo [1. ${ }^{a}$ ed.; orig. 1961].

Fanon, Frantz (2008), Pele negra, máscaras brancas. Salvador: EDUFBA. Tradução de Renato da Silveira [1. ${ }^{a}$ ed.; orig. 1952].

Foucault, Michel (2010), As palavras e as coisas. São Paulo: Martins Fontes. Tradução de Salma Tannus Muchail.

Ginzburg, Jaime (2011), "Linguagem e trauma na escrita do testemunho", in Wilberth Salgueiro (org.), O testemunho na literatura: representações de genocídios, ditaduras e outras violências. Vitória: EDUFES, 19-29. 
Grossberg, Lawrence (1997), Bringing It All Back Home. Essays on Cultural Studies. Durham: Duke University Press.

Guimarães, Antonio Sérgio (2019), “A recepção de Fanon no Brasil e a identidade negra”, in Julia Almeida; Adelia Maria Miglievich-Ribeiro; Heloísa Toller Gomes (orgs.), Crítica pós-colonial. Panorama de leituras contemporâneas. Rio de Janeiro: 7letras/FAPERJ, 33-54.

Hall, Stuart (2009), Da diáspora. Identidades e mediações culturais. Belo Horizonte: Editora da UFMG. Tradução de Adelaine La Guardia Resende et al.

Hardt, Michael (2015), "Para que servem os afetos?”, Intersemiose, IV(7), ix-xiv. Tradução de Luiz Roberto Leite Farias. Consultado a 28.01.2020, em http://www. neliufpe.com.br/wp-content/uploads/2015/10/001-1.pdf.

Herculano, Selene (2012), “Afetos, paixões e feminismo - A sociologia das emoções”. Niterói: Universidade Federal Fluminense. Consultado a 28.04.2020, em http:// www.professores.uff.br/seleneherculano/wp-content/uploads/sites/149/2017/09/ AFETOS_v2_PAIX\%C3\%95ES_E_FEMINISMO_A_SOCIOLOGIA_DAS_ EMO\%C3\%87\%C3\%95ES_fev2012.pdf.

Honneth, Axel (2003), Luta por reconbecimento. A gramática moral dos conflitos sociais. São Paulo: Editora 34. Tradução de Luiz Repa.

Latour, Bruno (1994), Jamais fomos modernos. Ensaio de antropologia simétrica. São Paulo: Editora 34. Tradução de Carlos Irineu da Costa.

Martins, Paulo Henrique (2019), "Sociologia na América Latina: giros epistemológicos e epistêmicos”, Sociedade e Estado, 34(3), 689-718. Consultado a 28.04.2020, em https://www.scielo.br/scielo.php?script=sci_arttext\&pid=S01 02-69922019000300689.

Mbembe, Achille (2011), “A universalidade de Frantz Fanon”, Artafrica. Consultado a 01.03.2020, em http://artafrica.letras.ulisboa.pt/uploads/docs/2016/04/18/ 5714de04d0924.pdf.

Memmi, Albert (2007), Retrato do colonizado precedido do retrato do colonizador. Rio de Janeiro: Civilização Brasileira. Tradução de Marcelo Jacques de Moraes.

Merleau-Ponty, Michel (2006), Fenomenologia da percepção. São Paulo: Martins Fontes. Tradução de Carlos Alberto Ribeiro de Moura.

Miglievich-Ribeiro, Adelia (2014), "Por uma razão decolonial: desafios ético-político-epistemológicos à cosmovisão moderna", Civitas - Revista de Ciências Sociais, 14(1), 66-80. Consultado a 01.03.2020, em https://www.scielo.br/scielo. php?pid=S1519-60892014000100005\&script=sci_arttext.

Miglievich-Ribeiro, Adelia (2017), "Pós-colonialismo", in Carlos Eduardo Sell; Carlos Benedito Martins (orgs.), Teoria sociológica contemporânea: autores e perspectivas. São Paulo: Annablume, 449-474.

Mignolo, Walter (2003), Histórias locais. Projetos globais. Colonialidade, saberes subalternos e pensamento liminar. Belo Horizonte: Editora da UFMG. Tradução de Marco Oliveira. 
Ortega, Francisco (2005), "Fenomenologia da visceralidade: notas sobre o impacto das tecnologias de visualização médica na corporeidade”, Cadernos de Saúde Pública, 21(6), 1875-1883. Consultado a 01.03.2020, em https://www.scielo.br/scielo. php?pid=S0102-311X2005000600037\&script=sci_abstract\&tlng=pt.

Ribeiro, Djamila (2017), O que é lugar de fala? Belo Horizonte: Letramento.

Rosa, Marcelo C. (2019), "Sociologias indígenas iorubá: a África, o desconcerto e ontologias na sociologia contemporânea”, Revista Estudos Históricos, 32(67), 389-408. Consultado a 01.06.2020, em https://www.scielo.br/scielo.php?script=sci_arttext\&pi $\mathrm{d}=$ S0103-21862019000200389.

Said, Edward (1990), Orientalismo. O Oriente como invenção do Ocidente. São Paulo: Companhia das Letras. Tradução de Tomás Rosa Bueno [1. a ed.; orig. 1978].

Said, Edward (1995), Cultura e imperialismo. São Paulo: Companhia das Letras. Tradução de Denise Bottmann.

Said, Edward (2003), Reflexões sobre o exílio e outros ensaios. São Paulo: Companhia das Letras. Tradução de Pedro Maia Soares.

Said, Edward (2004), Fora do lugar. São Paulo: Companhia das Letras. Tradução de José Geraldo Couto.

Said, Edward (2005), Representações do intelectual. São Paulo: Companhia das Letras. Tradução de Milton Hatoum.

Said, Edward (2007a), Covering Islam. How the Media and the Experts Determine How We See the Rest of the World. London: Vintage Books.

Said, Edward (2007b), Humanismo e crítica democrática. São Paulo: Companhia das Letras. Tradução de Rosaura Eichenberg.

Santiago, Silviano (1978), Uma literatura nos trópicos: ensaios sobre dependência cultural. São Paulo: Perspectiva.

Santos, Boaventura de Sousa (2004), "Para uma sociologia das ausências e uma sociologia das emergências", in Boaventura de Sousa Santos (org.), Conbecimento prudente para uma vida decente: um discurso sobre as ciências revisitado. São Paulo: Cortez, 777-821.

Sartre, Jean-Paul (1997), O ser e o nada. Ensaio de ontologia fenomenológica. Petrópolis: Vozes. Tradução de Thelma Lessa da Fonseca.

Schütz, Alfred (1979), "O mundo das relações sociais", in Helmut R. Wagner (org.), Fenomenologia e relações sociais: textos escolbidos de Alfred Schutz. Rio de Janeiro: Zahar, 159-195. Tradução de Angela Melin.

Seligmann-Silva, Márcio (org.) (2003), História, memória, literatura: o testemunbo na era das catástrofes. Campinas: Editora da Unicamp.

Stewart, Kathleen (2007), Ordinary Affects. Conceptualizing Relational Sociology. Ontological and Theoretical Issues. Durhan/London: Duke University Press.

Viveiros de Castro, Eduardo (2007), "Filiação intensiva e aliança demoníaca", Novos Estudos Cebrap, 77, 91-126.

Williams, Raymond (2011), Cultura e materialismo. São Paulo: Editora Unesp. Tradução de André Glaser. 
Artigo recebido a 03.06 .2020

Aprovado para publicação a 21.08.2020

\author{
Adelia Miglievich-Ribeiro \\ Programa de Pós-graduação em Ciências Sociais, Departamento de Ciências Sociais, Universidade \\ Federal do Espírito Santo | Programa de Pós-graduação em Sociologia, Universidade de Brasília | \\ Pesquisadora PQ-CNPq, nível 2 \\ Av. Fernando Ferrari, 514 - Goiabeiras, CEP 29075-910, Vitória - Espírito Santo, Brasil \\ Contacto: miglievich@pq.cnpq.br \\ ORCID: https://orcid.org/0000-0001-9736-2996
}

\section{The Post-Colonial Turn: Experiences, Trauma and Cross-Border Sensitivities}

This article proposes the "post-colonial turn" as a movement that is not limited to the epistemological debate or the aesthetic construction of the text. I argue that the post-colonial turn gives centrality to what I call knowledge-testimony, which occurs from the experience of a collective trauma: colonialism-racism. In this perspective, I argue that their categories are formulated from other places of speech, which are, at the same time, places of affections. In dialogue with the "affective turn", I explain the iconic trajectories of Frantz Fanon and Edward Said in order to expose the experiences of exile, diaspora, suffering and hybridity that configure the special structure of feelings in Raymond Williams' terms that imbues such intellectual productions. Therefore, the return to the post-colonial founding authors allows for the extracting of provocations which promote the vitality of the current post-colonial turn.

Keywords: biographies; Edward Said; Frantz Fanon; place of speech; postcolonialism; worldview.

\section{Le tournant postcolonial : expériences, traumatismes et sensibilités transfrontalières}

Dans cet article, je postule le «tournant postcolonial » comme un mouvement qui ne se limite pas au débat épistémologique ou à la construction esthétique du texte. Je soutiens que son différentiel réside dans la centralité qui donne à ce que j'appelle « connaissance-témoignage » à partir de l'expérience d'un traumatisme collectif: le colonialisme-racisme. Ainsi, leurs catégories sont formulées à partir d'autres lieux de la parole, qui sont surtout des «lieux d'affections ». Dans le dialogue avec le « tournant affectif », j'expose les trajectoires emblématiques de Frantz Fanon et Edward Saïd, mettant en évidence les expériences de l'exil, de la diaspora et de l'hybridité qui configurent, dans les termes de Raymond Williams, la structure spéciale des sentiments qui imprègne ces productions intellectuelles. Le retour aux auteurs fondateurs du postcolonial permet donc d'extraire des provocations qui favorisent la vitalité du tournant postcolonial, corroborant sa situation actuelle.

Mots-clés: biographies; Edward Said; Frantz Fanon; place de la parole; postcolonialisme; vision du monde. 
